Level of satisfaction with positive leisure time And its relation to psychological well-being and some demographic characteristics for the elderly

"Prof. Dr. /Hossam Abdel Aziz gouda

** Dr. /Mustafa Amin Al Ashqar

Abstract

The research aims at determining the level of satisfaction with positive leisure time and its relation to psychological well-being and some demographic characteristics among the elderly. The researchers used the descriptive approach (correlational relations). The sample included (256) adult (11) sports clubs in Dakahlia Governorate The researchers prepared Personal interview form, Demographic Characteristics Form, Satisfaction with Positive Leisure Time Scale and Psychological well-being Scale as data collection tools.

The most important results: High level of satisfaction with positive leisure time and psychological well-being among the elderly, The level of satisfaction with positive leisure time is related to level of psychological well-being and some demographic characteristics. The study recommended diversity and continuity in the provision of leisure activities in sports clubs to reach psychological well-being and the development of a strategy to activate and develop recreational and recreational activities involving older persons with officials of sports and recreational institutions.

Keywords: Satisfaction, Positive Leisure Time, Psychological wellbeing, elderly.

\title{
Introduction:
}

The human societies are witnessing many factors and variables that affect all groups of society in the light of technological development and

the information revolution, especially elderly, because of their importance and effective role in building society according to their capabilities

" Assistant Prof., sport recreation department, faculty of physical education, Mansoura university, Egypt

" Lecturer, sport psychology department, faculty of physical education, Mansoura university, Egypt

Assiut Journal For Sport Science Arts 
and potentials. Therefore, societies seek to occupy their leisure time, With happiness and satisfaction.

Salem, M. \& Mustafa, W. (2008); Shows The aging stage is characterized by a difference in the psychological, social, physical and mental characteristics of the previous stages, which are affected by the conditions of the surrounding society and are based on the basic needs to satisfy them so as not to lead to many of the problems facing the elderly.

The exposure of of the elderly to persistent and chronic problems and pressures leads to negative outcomes ranging from sleep disorders and mental health disorders. When older people are unable to respond effectively to stressful challenges, they cause effects of mental neurodegenerative disorders that are responsible for total disability.

Egypt is committed to the rights of the elderly. The Egyptian Constitution states in Article (83) of Part Three; "Public Rights and Duties": "The State shall guarantee the rights of the elderly, And to enable them to participate in public life. The State takes into account the needs of the elderly and encourages civil society organizations to participate in the care of the elderly, as regulated by law". (Constitution of Egypt, 2014)

Therefore, mental health scientists are keen to move away from the negative answer of problems, disorders and imbalances, and focus on the positive aspects as an independent specialization of self-esteem, empathy, optimism, environmental compatibility, social support and satisfaction with life as important indicators of wellbeing. (Shuwaikh, H., 2010; Kapikiran, N., 2011; Tamannaeifar, M. \& Motaghedifard, M., 2014) This concern has led to the identification of the essential features of wellbeing: (Hedonic), and known as (subjective well-being), based on achieving happiness and pleasure as a primary goal of life, striving for excellence or mobilizing energies (Eudaimonic) and known as (psychological well -being) and is based on the development of individual capabilities that are 
in line with public values. (Negovan, V., 2010; Lundqvist, C., 2011)

Novo, M. \& et al. (2010); that the concept of mental well-being includes a sense of psychological wellbeing as a basis for quality of life, and a way of assessing past and present life. These assessments include emotional reactions to life and mood events and judgments regarding the way the individual lives.

Shand, S. \& et al. (2013); That the concept of mental well-being is one of the indicators that reflect the positive psychological performance, which is greater than mental health, it defines the relationship of the individual itself of the acceptance and uniqueness and awareness of them to achieve independence, despite enjoying good relations with others saturated with security and mutual respect seeking to achieve the goals and goals of life adopted by Through the exploitation of all environmental opportunities and overcome the obstacles faced, in order to achieve progress and continuity.
Therefore, it is possible to check the access of older persons to a high level of psychological well-being by measuring some of the main components, such as the goal of life, self-acceptance, selfindependence, compatibility with the environment and interactive relationships with others in leisure, The daily vacuum and the variety of activities they practice.

Hassanein, M. \& Ismail, K. (2009); suggests that the practice of older people for positive leisure activities increases community communication, selfconfidence, helps them to cope with their problems, acquire new skills, acquire a lot of knowledge and abilities that Enabling him to regain his natural life to achieve a better life.

Katrin, D. (2016); affirms that there is a positive role to exercise and invest leisure activities in improving the mood, promoting self-care, increasing social communication, relaxation, physical health and psychological well-being, and giving them happiness and satisfaction. 
Therefore,

the psychological satisfaction of the elderly can be achieved when meeting their needs for leisure time and linking them to elements and educational dimensions in discovering and modifying the lifestyle, emotional in the sense of success and achievement and self expression, collective interaction and establishing new relationships, dynamic in renewing activity and vitality and improving health, The information he / she is aware of.

The topics of leisure time and the mental health of the elderly are worthy of research and need to involve the efforts of researchers in various scientific disciplines in order to understand the various dimensions of this category which occupies an important position and an increasing interest in studies and humanities. The situation of older persons suffering from a lack of satisfaction with their physical, social, mental and psychological needs.

Therefore,

the researchers conducted a survey by means of a semi-formal interview form with (20); (13) males, (7) females from some of the sports clubs in Dakahlia governorate, in order to identify their answers to some questions related to the research topic Daily leisure, preferences for leisure activities and expected results from leisure activities. (Appendix C)

The increase in daily leisure time, the awareness of older people about leisure investment, the preference for social, sports and cultural activities for other activities, and the expected results showed a sense of pleasure, happiness and personal satisfaction.

For the importance of positive activities in leisure time and their role in improving mental health, especially psychological wellbeing, the researchers learned of some scientific research, according to the results of the study of Zambianchi, M. \& et al. (2009); That some demographic factors affect the mental well-being that can be predicted through mental health, and the results of the study Metin, A. \& et al. (2018); That well-being directly affects leisure and satisfaction with 
life and indirectly the happiness and responsibility of both satisfaction with leisure and satisfaction with happiness and the results of the study of Teresa, F. \& Ana, T. (2018); Leisure time attitudes are an important indicator of leisure satisfaction, leisure satisfaction is largely expected in all dimensions of positive performance, a relationship between satisfaction with leisure time and self-esteem.

As recommended by Elzahaby, M. \& et al. (2013); Sponsorship of older persons through leisure investment and awareness of the importance of recreational hobbies, and the study of Po-Ju, C. \& et al. (2014); Increased exercise of older leisure activities, where they can contribute to improving health aspects, and study Anzi, H. (2015); Involvement of older persons in activities aimed at promoting self-esteem and alleviating negative psychological symptoms and the study of Teresa, F. \& Ana, T. (2018); Developing positive attitudes towards leisure to increase levels of satisfaction with leisure time and the importance of leisure time satisfaction for the positive performance of individuals.

As a result of the nature of contemporary life and the psychological pressures and many different problems, comes positive psychology to put forward many positive psychological concepts that help the elderly to face the pressures and problems and reduce the intensity of self, and comes at the forefront of these concepts the term psychological well-being, The study aims to determine the level of satisfaction with leisure time and its relation to psychological well-being and demographic characteristics.

\section{Research Aim:}

The aim of the research is to determine the level of satisfaction with positive leisure time and its relation to psychological well-being and some demographic characteristics of the elderly.

\section{Research questions}

- What is the level of satisfaction with positive leisure time of the elderly?.

- What is the level of psychological well-being of the elderly?.

- What is the relationship between satisfaction with 
positive leisure time and psychological well-being of the elderly?.

- What is the relationship between satisfaction with positive leisure time and some demographic characteristics of the elderly?.

- What is the significance of differences in satisfaction with positive leisure time and psychological well-being according to Gender of the elderly?.

- What is the significance of differences in satisfaction with positive leisure time and psychological well-being according to marital status of the elderly?.

- What is the significance of differences in satisfaction with positive leisure time and psychological well-being according to income level of the elderly?

\section{Research terms}

- Satisfaction with positive leisure time (SPLT): "A positive feeling between what the elderly want and what they have already achieved as a result of constructive practices in times of freedom from commitments to achieve happiness". (Procedural definition) $\begin{array}{lrr}\text { - Psychological } & \text { well- } \\ \text { being(PWB): } & \text { "A } & \text { semi- } \\ \text { permanent positive } & \text { inner }\end{array}$ feeling reflects satisfaction with life, psychological reassurance, joy, enjoyment, internal control, self-realization and the ability to deal with problems and difficulties efficiently and effectively". (Abdel Maqsoud, A., 2006)

- Elderly: "The members of the post-sixties age group as a period of gradual decline in motor and mental abilities and physiological, social and psychological changes compared to previous age stages". (Elzahaby, M \& . Gouda, H., Y. 17 )

\section{Methods:}

\section{Approach:}

The researchers used the descriptive approach in the method of studying the interrelationships with its steps and procedures.

\section{Participants}

The current research community is determined in the category of the elderly age (60) years and above, and practitioners of leisure activities and frequent sports clubs in Dakahlia Governorate. 
The study sample was selected by simple random sampling method. The survey was conducted on (37) aged excluded from the basic sample. The basic sample of the research included (256) adult (11) sports clubs in Dakahlia Governorate with an Mean of (65.16). (Appendix B)

Table (1) shows; The highest rate was $(56.25 \%)$ for older males, the lowest percentage was $(43.75 \%)$ for females, the highest rate was $(59.38 \%)$ for unmarried elderly, (40.62\%) of married elderly, while the highest percentage $\quad(50.00 \%)$ of middle-income elderly, and the lowest proportion $(18.75 \%)$ of high income earners.

Table (1): Description of the Basic Research Sample ( $=256)$

\begin{tabular}{|c|c|c|c|c|c|}
\hline \multicolumn{2}{|c|}{$\begin{array}{l}\text { Demographic } \\
\text { characteristics }\end{array}$} & $\mathbf{N}$ & percentage & Mean \pm & SD* \\
\hline Gender & $\begin{array}{c}\text { Male } \\
\text { Female }\end{array}$ & $\begin{array}{l}144 \\
112\end{array}$ & $\begin{array}{l}\% 56.25 \\
\% 43.75\end{array}$ & 1.07 & 0.50 \\
\hline $\begin{array}{l}\text { Marital } \\
\text { status }\end{array}$ & $\begin{array}{c}\text { Married } \\
\text { Unmarried }\end{array}$ & $\begin{array}{l}104 \\
152\end{array}$ & $\begin{array}{l}\% 40.62 \\
\% 59.38\end{array}$ & 1.41 & 0.49 \\
\hline $\begin{array}{c}\text { Income } \\
\text { level }\end{array}$ & $\begin{array}{c}\text { Low } \\
\text { Middle } \\
\text { High }\end{array}$ & $\begin{array}{c}80 \\
128 \\
48\end{array}$ & $\begin{array}{l}\% 31.25 \\
\% 50.00 \\
\% 18.75\end{array}$ & 1.88 & 0.70 \\
\hline
\end{tabular}

\section{Data collection tools:}

The researchers prepared data collection tools to measure the search variables, Personal interview form, Demographic Characteristics Form, Satisfaction with Positive Leisure Time Scale, psychological well-being Scale, as follows:

\section{Personal interview form:}

The interview was conducted with (20) aged, with the aim of identifying the size of daily leisure, preferences for leisure activities and the expected results of leisure activities. This helped to confirm the problem of research and construction of data collection tools.(Appendix C)

\section{Demographic Characteristics} Form:

The researchers reviewed some of the previous studies related to the characteristics of the older age group, in order to determine 
some

demographic characteristics suitable for the nature of the research variables, such as: Hawkins, B. \& et al. (2004) ،Janelle, G. \& Kryss, M. (2009), Zambianchi, M. \& et al. (2009), Elzahaby, M. \& Gouda, H. (2016), Hülya, Ö. \& Bahar, K. (2016), Yu-Jin, C. (2018); and stability (gender, marital status, income level) as demographic characteristics of the elderly. (Appendix D)

- Satisfaction with Positive Leisure Time Scale:

Determining the Aim of the scale; Determining the level of satisfaction with positive leisure time of the elderly.

A number of scientific references and studies related to leisure time were examined, with the aim of determining the dimensions of the scale, such as AlFadel, A. (2004), Katherine, B. \& Beggs, B. (2006), Alhamahmi, M. \& Abdul Aziz, A. (2009), Abdel Aziz, M \& Batrawi, A. (2013), Silvia, M. \& et al. ( 2016), Tebessüm, A. \& et al. (2016), Al-Samnoudi \& et al. (2018); A number of (5) dimensions were drawn to construct the scale, namely: (educational dimension, emotional dimension, collective dimension, motor dimension, information dimension).

Items group was placed taking into account the accuracy in the selection of items by the independence of each individual from another and easily formulated and away from the complexity and repetition under each dimension in the scale of (42) items in the initial image. (Appendix E)

Items of the scale was presented to (7) of the experts specialized in recreation, sports psychology and mental health to express the opinion with approval or non-approval and any other suggestions. (Appendix A)

The researchers have agreed a percentage $(70.00 \%)$ Experts to accept items. (Appendix F)

Based on the opinions of the experts, items of the scale consists of (37) individual distributed over (5) dimensions by (29) positive items and (8) negative items. By estimating the responses using the fivedimensional Likert scale according to the levels of (Very satisfied, Satisfied, Undeeided, Dissatisfied, Very dissatisfied) with grades $(5,4,3,2,1)$ for positive items and the opposite for negative items.

The researchers used for calculating validity sincerity of internal consistency and 
Cronbach alpha coefficient for calculating reliability, the validity coefficient was $(0.62$ : $0.82)$, Self-validity was $(0.84$ : $0.91)$ and the coefficient of reliability was (0.70: 0.83$)$. (Appendix G)

After

Scientific

transactions, items of the scale consists of (30) individual distributed over (5) dimensions by (24) positive items and (6) negative items, with a minimum of (30) degrees and a maximum of (150) degrees in the final image. (Appendix $H$ ) - psychological well-being Scale:

Determining the Aim of the scale; Determining the level of psychological wellbeing of the elderly.

A number of scientific references and studies related to leisure time were examined, with the aim of determining the dimensions of the scale, such as Negovan, V. (2010)، Novo, M. (2010)، Kapikiran, N. (2011), Shand, S. \& et al. (2013), Sherry, L. \& Bryan, J. (2013), 34. Yassin, H. \& et al.(2014), 20. Kharnoub, F. (2016); A number of (5) dimensions were drawn to construct the scale, namely: (Purposeful Life dimension,
Positive Relationships dimension, dimension, Self-Acceptance dimension, Independence compatibility dimension).

Items group was placed taking into account the accuracy in the selection of items by the independence of each individual from another and easily formulated and away from the complexity and repetition under each dimension in the scale of (60) items in the initial image. (Appendix I)

Items of the scale was presented to (7) of the experts specialized in recreation, sports psychology and mental health to express the opinion with approval or non-approval and any other suggestions. (Appendix A)

The researchers have agreed a percentage $(70.00 \%)$ Experts to accept items. (Appendix J)

Based on the opinions of the experts, items of the scale consists of (53) individual distributed over (5) dimensions by (35) positive items and (18) negative items. By estimating the responses using the fivedimensional Likert scale according to the levels of 
(Strongly Agree, Agree, Indifferent, Disagree Strongly Disagree) with grades $(5,4,3$, $2,1)$ for positive items and opposite for negative items.

The researchers used for calculating validity sincerity of internal consistency and Cronbach alpha coefficient for calculating reliability, the validity coefficient was $(0.56$ : $0.82)$, Self-validity was $(0.84$ : 0.92 ) and the coefficient of reliability was $(0.71$ : 0.84$)$. (Appendix K)

After

Scientific transactions, items of the scale consists of (44) individual distributed over (5) dimensions by (31) positive items and (13) negative items, with a minimum of (44) degrees and a maximum of (220) degrees in the final image. (Appendix L)

\section{Survey Study}

The researchers conducted an exploratory study on a sample of (37) aged from outside the basic study sample and within the research community in the period from $(04 / 01 / 2018)$ to $(11 / 01 / 2018)$. The aim was to identify the clarity of instructions for data collection tools, The formulation of items for the level of understanding of the sample and the conduct of scientific transactions. The results showed the clarity of the instructions, the appropriate wording of the items for the level of understanding of the sample and the scientific transactions of the data collection tools were carried out.

\section{Basic Study}

The researchers applied the criteria on the basic research sample (256) aged, after confirming the scientific transactions, in the period from $(25 / 01 / 2018)$ to $(01 / 02 / 2018)$. After the completion of the application process Data collection, organization, data collection and scheduling of the appropriate statistical treatments were collected.

\section{Statistical Methods}

The researchers used the statistical program SPSS (v.22), for the following scientific coefficients and statistical treatments: Percentage, Mean, Standard Deviation, Simple correlation coefficient, Cronbach alpha coefficient, $\mathrm{T}$ test of differences between two independent sample mean, $F$ test of differences between independent sample mean and 
the L.S.D for the mean difference between independent sample mean. Based on reached of previous studies, according to the FiveLikert estimation of the responses of elderly to the

\section{Table (2).}

Table (2): Determination the levels of Satisfaction with Positive Leisure Time Scale and psychological well-being Scale for elderly

\begin{tabular}{|c|c|c|c|}
\hline $\mathbf{N}$ & Mean \pm & Percentage & level \\
\hline 1 & $1 . \vee 9: 1 . \cdots$ & 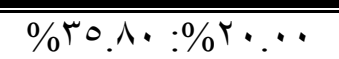 & Very low \\
\hline$r$ & $r .09: 1.1$. & $\% 01 . \wedge .: \% \%^{4} . .$. & Low \\
\hline$r$ & r. & $\%$ \%マ.^.:\%०Y... & Medium \\
\hline$\xi$ & ร.19:Y.ร. & 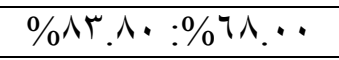 & High \\
\hline 0 & O...: : . . & $\%) \cdots, \cdots: \%^{\wedge \varepsilon}, \cdots$ & Very high \\
\hline
\end{tabular}

\section{Results}

In order to achieve the aim of research and in response to questions raised and within the sample of the research and the methodology used, the researchers show their Results of the classified, as follows:

- What is the level of satisfaction with positive leisure time of the elderly?. (Appendix M)

Table (3) shows; The level of satisfaction with the positive leisure time of the elderly in general and in the emotional dimension, the collective dimension, the motor dimension is (high), this may be due to the exercise of the items of the Satisfaction with Positive Leisure Time Scale and psychological well-being Scale, levels were identified for use in determining the level, as

\section{shown in}


While the level of satisfaction with the positive leisure time in the educational dimension, the information dimension is (Medium). This may be due to the accumulated accumulation of culture as a result of the multiple attitudes experienced by the elderly at different age levels, as well as the older role of education for those who are younger The result of different educational and life experiences and the priority to satisfy other desires and needs.

This is consistent with the study results of Katherine, B., \& Beggs, B. (2006), Janelle, G. \& Kryss, M. (2009) and Gun-Sang, C. \& Eun-Surk, Y. (2013); That older persons participate in leisure activities, the diversity of leisure activities of the elderly, leisure and recreational activities play an important role in the lives of older persons and the high level of satisfaction in leisure time.

This is also consistent with the study results of the Sherry, L. \& Bryan, J. (2013), Elzahaby, M. \& Gouda, H. (2016) and Yu-Jin, C. (2018); In the awareness of the elderly of the importance of investing leisure time, an increase in the amount of time spent in leisure activities, and participation in leisure are positively related to one's physical health, participation in leisure activities is often negative And positive (social and physical).

- What is the level of psychological well-being of the elderly?. (Appendix N)

Table (4) shows; The level of psychological wellbeing of the elderly in general and Purposeful Life Dimensions, positive relationships Dimensions and self-acceptance Dimensions is (high), This may be due to the perception of the elderly to be better at dealing with negative feelings and trust in others By maintaining

previous friendships and making new friendships as well as selfunderstanding and satisfaction of desires, which improves the feeling of reassurance and happiness to be a life of value and aim sought by the elderly and the increase in the age of time adds to the balance of older growth and accumulation of knowledge in various areas to achieve mental well-being . while the level of psychological well-being in 
Independence Dimensions, Environmental compatibility Dimensions is (Medium), This may be due to the adoption of the elderly to opinions and accept the views of various friends and family, and the ability to benefit from the surrounding positions, to confront the pressures and identify activities commensurate with his abilities and readiness in The surrounding environment.

This is consistent with the study results of Janelle, G. \& Kryss, M. (2009) and Sherry, L. \& Bryan, J. (2013); The high level of satisfaction with life, participation in hobbies, handicrafts and visiting friends was positively associated

Increasing psychological well-being and low levels of symptoms of depression of all elderly.

- What is the relationship between satisfaction with positive leisure time and psychological well-being of the elderly?. (Appendix O)

Table (5) shows; That there is a statistically significant correlation between the total score of the satisfaction with positive leisure time scale and the total score of the psychological well-being scale, The calculated value (r) is greater than the tabular value at a significant level (0.05), This may be due to Recognizing the importance of investing leisure time by activating the various activities that concern the psychological, social, Motor, educational and informational aspects of them while raising morale, especially if the exercise of leisure activities in the leisure time with a group of family members and friends, which brings happiness and pleasure and psychological compatibility Otherwise a sense of security and satisfaction, so the higher the level of satisfaction with the positive leisure time in the elderly the higher the level of psychological well-being to have.

This is consistent with the study results of Janelle, G. \& Kryss, M. (2009), Cheng-Yu T. \& et al. (2012) and GunSang, C. \& Eun-Surk, Y. (2013); The high level of satisfaction in leisure time and satisfaction with life, the correlation between satisfaction with leisure time and spiritual well-being, the 
correlation

between

satisfaction with leisure time and self-esteem, the greater the time, frequency and intensity of leisure and leisure activities Happiness in the life of the elderly.

This is also consistent with the study results of Sherry, L. \& Bryan, J. (2013), Tebessüm, A. \& et al. (2016) \& Yu-Jin, C. (2018); Participation in leisure is positively related to the individual's physical health and general satisfaction with life, the diversity of leisure activities is associated with high psychological wellbeing and an increase in the amount of time spent in leisure activities has led to an increase in the value of leisure activities. Satisfaction with life and the high level of satisfaction with life as a result of high satisfaction with leisure time for individuals in general.

- What is the relationship between satisfaction with positive leisure time and some demographic characteristics of the elderly?. (Appendix P)

Table (6) shows; That there is a statistically significant correlation between the total score of satisfaction with positive leisure time and the demographic characteristics associated with marital status and Income level, The calculated value $(r)$ is greater than its tabular value at a significant level (0.05), This may be due to the presence of the elderly with their peers is one of the most powerful human desires of social nature, for which the relationship is related to a long period of time. Level of Financial income allows The opportunity for the elderly to participate and practice The greater the level of satisfaction with positive leisure time of the elderly, and the higher the level of income, the higher the level of satisfaction with positive leisure time of the elderly.

For marital status, this is consistent with the study results of Katherine, B., \& Beggs, B. (2006), Tebessüm, A. \& et al. (2016) and Yu-Jin, C. (2018); in the effect of social and marital status characteristics on leisure satisfaction in elderly. While this is different from the study results by Janelle, G. \& Kryss, M. (2009) and Tebessüm, A. \& et al. (2016); There are nonsignificant differences between 
social variables in leisure time and satisfaction with life.

For the income level property, this is consistent with the study results of Elzahaby, M. \& Gouda, H. (2016), Tebessüm, A. \& et al. (2016); The effect of the income level on the sense of life as recreational participation increases in leisure time and affects satisfaction with leisure time.

There is non statistical correlation between the total score of the positive leisure time and gender as demographic characteristics. The calculated value (r) is less than the tabular value at a significant level (0.05), This may be due to the fact that leisure activities are the right of every individual Male or female, for the similarity of ways of investing leisure time in males and females in achieving happiness, pleasure and personal satisfaction.This contrasts with the study results of Hawkins, B. \& et al. (2004); on the effect of gender on participation in leisure activities.

While agreeing with what he said Aweys, M. (2008); that everyone has the right to free time, to enjoy leisure time freely and to provide recreational activities in leisure, as well as with Alhamahmi, M. \& Abdul Aziz, A. (2009), about The World Association of Recreation and Recreation; that everyone has the right to prepare for him the means to participate in recreational activities in his spare time, such as physical sport and enjoy the life of the void and the arts without considerations of age. This is also consistent with the study results of Tebessüm, A. \& et al.. (2016); Gender variable does not affect participants' satisfaction with leisure time.

- What is the significance of differences in satisfaction with positive leisure time and psychological well-being according to Gender of the elderly?. (Appendix Q)

Table (7) shows; That there is a differences non statistically significant between male and female elderly in satisfaction with positive leisure time scale and psychological well-being scale. The calculated value $(\mathrm{t})$ is less than the tabular value at a significant level (0.05), This is because the awareness of male 
and female elderly of the concept, objectives, and characteristics of positive leisure activities. The practice of leisure activities is available to all, which is entitled to happiness and a sense of personal satisfaction and Governmental, nongovernmental institutions are committed to providing services and activities for the elderly in accordance with the provisions of the Egyptian Constitution.

This is consistent with the study results of Janelle, G. \& Kryss, M. (2009), Sherry, L. \& Bryan, J. (2013), Yassin, H. $\&$ et al. (2014) and Tebessüm, A. \& et al. (2016); The level of leisure and satisfaction with life and psychological wellbeing varies according to the gender variable.

- What is the significance of differences in satisfaction with positive leisure time and psychological well-being according to marital status of the elderly?. (Appendix R)

Table (8) shows; That there a statistically significant differences between married and unmarried elderly in satisfaction with positive leisure time scale and psychological well-being scale in favor of married elderly. The calculated value of $(t)$ is greater than its tabular value at a significant level (0.05), This may be due to the fact that the desire for the elderly to be present with their peers is one of the most powerful human desires for the social nature with which the relationship is connected for a long period of time through the various stages of life, especially the husband / wife, and the need for support and social assistance, The satisfaction of the elderly about the practice Positive leisure activities thus achieve a high level of mental health, especially psychological wellbeing.

This is consistent with the study results of Katherine, B., \& Beggs, B. (2006), Tebessüm, A. \& et al. (2016) and Yu-Jin, C. (2018); The marital and social situation affects satisfaction in leisure and life satisfaction of the elderly.

This is also consistent with the study results of Po,J. $\&$ et al. (2014); leisure activities mediate the relationship between social relations and health of older 
persons, the existence of positive social relationships with greater involvement in recreational activities.

- What is the significance of differences in satisfaction with positive leisure time and psychological well-being according to income level of the elderly?. (Appendix S)

Table (9) shows; That there a statistically significant differences of the elderly with the high, middle and low income level in satisfaction with positive leisure time scale and psychological well-being scale, The calculated value $(\mathrm{F})$ is greater than the tabular value at a significant level (0.05), This may be due to the association of leisure time with the value of income in determining the times of activity in certain places. In order to know the direction of the differences, the distance comparison was used by testing the least significant difference of LSD, as shown in Table (10).

Table (10) shows; That there a statistically significant differences between the mean responses of the elderly with the high, middle and low income levels in the measure of satisfaction with positive leisure time scale and psychological well-being scale for the benefit of the elderly with high income level, This may be due to high income level Helps to spend the leisure of the elderly in a large and varied because of the requirements for the exercise of leisure activities, especially when the frequency of private places for consecutive periods, which contributes to the psychological well-being of the elderly to a high degree.

This is consistent with the study results of Elzahaby, M. \& Gouda, H. (2016), Hülya, Ö. \& Bahar, K. (2016) and Tebessüm, A. \& et al. (2016); High impact of high-income elderly on a sense of life, with increased recreational participation in leisure time, satisfaction with leisure and satisfaction with life.

\section{Conclusions}

Based on the results of the research, and in view of methodology, within the sample, data collection tools and statistical methods, the researchers provide the following conclusions: 
- The high level of satisfaction with positive leisure time of the elderly.

- The high level of psychological well-being of the elderly.

- The level of satisfaction with positive leisure time is related to the level of psychological well-being. The higher the level of satisfaction with positive leisure time, the higher the level of psychological wellbeing of the elderly.

- The demographic characteristics associated differing with the level of satisfaction with positive leisure time and psychological well-being of the elderly.

- A high level of satisfaction with positive leisure time and psychological well-being regardless of gender.

- Marital status increases the level of satisfaction with positive leisure time and psychological well-being of older married couples.

- High-income of the elderly are satisfied with positive leisure and psychological wellbeing.

\section{Recommendations}

In view of aim, questions of research, Approach and sample of the elderly, the researchers provide recommendations as follows:

- Use data collection tools to measure the level of satisfaction with positive leisure time and the level of psychological well-being of the elderly.

- Diversity and continuity in the provision of leisure activities in clubs.

- Use elderly as volunteer in educational leisure activities.

- Participation of sports clubs in the General Union of Sport for All.

- Preparation of a guide under the supervision of specialists qualified to work with the pioneers (elderly) with various activities suitable for them in and outside sports clubs.

- The need for attention of recreational and sports institutions to the elderly, through:

- Establish a recreational city for the elderly that provides all forms of positive practice for different activities.

- Providing volunteer leadership to work with older persons, which is an important factor contributing to the activation of practice within recreational activities. 
- Exchange experiences and experiences with some $A r a b$ and international countries that provide support and care for the elderly and benefit from the internal regulations, charters and regulations governing the work of institutions concerned with the elderly.

- Develop a strategy to activate and develop recreational and recreational activities involving the elderly with officials of sports and recreational institutions, through:

* Environmental analysis of sports clubs in the surrounding community and their leisure activities.

* Preparation of means of advertising and advertising on leisure activities.

* Provision of tools and equipment for practicing various leisure activities.

* Provide places of practice of a privacy nature.

* Provide professional supervisors and qualified academically.

* Propose various activities and programs at specific time frames.

* Monitoring and evaluating activities and programs for elderly.
- Conducting scientific research related to recreational and leisure activities among older persons with the social, psychological and mobility variables of the elderly.

\section{References}

\section{1- Abdel Aziz, M \& Batrawi,}

A. (2013): Introduction to Recreation and Free Time, Mahe for publication and distribution, Alexandria.

2- Abdel Maqsoud, A. (2006). Psychological happiness and its relationship to some psychological variables in a sample of adolescents of both sexes, Journal of Psychological and Educational Research, Faculty of Education, University of Menoufia, No. (2).

3- AlFadel, A. (2004): Leisure Satisfaction Scale: A Comparative Study, Um AlQura University Journal of Educational, Social and Human Sciences, Saudi Arabia, Vol. (16), No.(1), pp:(220-224).

\section{4- Alhamahmi, M. \& Abdul} Aziz, A. (2009): Recreation between theory and practice, edition (6), the Book Center for Publishing, Cairo

5- AlSamnoudi \& et al. (2018): Entrance of the

\section{Assiut Journal For Sport Science Arts}


Recreation Sports, Al-Eyman Library, Mansoura.

6- Anzi, H. (2015). The Effect of a Sports Recreation Program on the Degree of Satisfaction with Life and Balanced Level of Older Persons, Scientific Journal of Physical Education and Sport Sciences, Faculty of Physical Education for Boys, Helwan University, Vol. (73), No. (2), pp:(126-146).

7- Aweys,

M. (2008).

Recreation and leisure time (Letter to Young People over sixty), for printing and publishing police presses and distribution, Cairo.

8- Cheng-Yu T., Li-Wei L., \& Ming-Tsang W. (2012). Relationship among Leisure Satisfaction, Spiritual Wellness, and Self-Esteem of Older Adults, World Academy of Science, Engineering and Technology, International Journal of Psychological and Behavioral Sciences, Vol. (6), No. (12), pp:(3659-3662).

9- Elzahaby, M \& .Gouda, H. (2016) Management of Leisure time and its relation with the recreational participation and the meaning of life for the Elderly, International Journal of Sport Scientific \& ARTS (IJSSA), on line Edition,
Faculty of Physical Education for girls in gezira, helwan university, No. cod. (305).

\section{0- Elzahaby, M., Mansour,} N. \& Gouda, H. (2013): Patterns of recreational hobbies and their relationship to optimism, pessimism and social communication for the elderly, The 11th International Scientific conference for Physical Education and Movement Sciences" Sport in Theory\& Practice, Faculty of Physical Education for Boys, Alex university, Vol. (2016), pp:(64-77).

11- Gun-Sang, C. \& EunSurk, Y. (2013). Analysis on leisure patterns of the preelderly adults, Journal of Exercise Rehabilitation, Vol. (9), No. (4), pp:(438-445).

12- Hassanein, M. \& Ismail, K. (2009). Sport free time for the elderly, Dar elfikr elarabi, Cairo, Egypt, pp:( $\leqslant 0)$.

13- Hawkins, B., Foose, A. \& Binkley, A. (2004). Contribution of Leisure to the Life Satisfaction of Older Adults in Australia and the United States, World Leisure Journal, Vol. (46), No. (2), pp:(4-12).

14-http://www.sis.gov.eg/

Newvr/consttt\%202014.pdf,State 
Information Service, Constitution of the Arab Republic of Egypt (2014). 15/2/2018, 9.45 P.M.

15-Hülya, Ö. \& Bahar, K. (2016). An Analysis of the Factors that Affect the Life Satisfaction of Elderly Turks Living in Australia, Journal of Administrative Sciences and Policy Studies, Vol. (4), No. (1), pp:(21-35).

16- Janelle, G. \& Kryss, M. (2009). Influences on Leisure and Life Satisfaction of Elderly People, Journal Physical \& Occupational Therapy In Geriatrics, Vol. (15), No. (4), pp:(1-16).

17- Kapikiran, N. (2011). Focus on positive and negative information as the mediator of the relationship between empathy tendency guilty and psychological well-being in university students, Educational Sciences :Theory and Practice, Vol. (11), No. (3), pp:(1141-1147).

18- Katherine, B. \& Beggs, $B$. (2006). Leisure Satisfaction of Older Adults, Article, Activities Adaptation \& Aging, Publisher: Taylor \& Francis (Routledge), Vol. (1), PP: (1-18).
19- Katrin, D. (2016), Physical exercise and psychological well being, $\mathrm{Br} \mathbf{J}$ Sports Med, Vol. (32), No. (1), pp:(111-120).

20- Kharnoub, F. (2016). Psychological Wellbeing and its Relation to Emotional Intelligence and Optimism (A Field Study in a Sample of the Students of the Faculty of Education at Damascus University), Journal of the Federation of Arab Universities for Education and Psychology, Damascus University, Faculty of Education, Vol. (14), No.(1), pp:(217-242).

21- Lundqvist, C. (2011). Well-being in Competitive Sports -The Feel -Good Factor? A Review of Conceptual Considerations of Well-being, International Review of Sport and Exercise Psychology, Vol. (4), No. (2), pp:(127-159).

22- Metin, A., Mehpare, T. \& Mehmet, T. (2018). Examining Relationships Among Well-being, Leisure Satisfaction, Life Satisfaction, and Happiness, Journal of Medical Research \& Health, Vol. (7), No. (4), pp:(49-59).

23- Negovan, V. (2010). Dimensions of 
Students`Psychological WellBeing and Their Measurement: Validation of A Students Psychological well-being Inventory ,Europe`Journal of Psychology, Vol. (2), No. (1), pp:(85-104).

24- Novo, M., Vargas, R.. Alex, S., Karing, R., Maryori, V. \& Castellanos, O. (2010). Psychological well-being and quality of life in Patients treatedfrom thyroid cancer after surgery, Terapia Psicologica, Vol. (28), No. (1), pp:(69-84).

25- Po-Ju, C. Linda, W. \& Yeqiang, Lin(2014).,Social Relationships, Leisure Activity, and Health in Older Adults, Health Psychology, Vol. (33), No. (6), pp:(516523).

26- Salem, M. \& Mustafa, W. (2008). Caring the elderly in the family and society and its relation with satisfaction about life, atheist 11th International Scientific Conference of Social Service, Egypt, pp:(63-64).

27- Shand, S., Wahiba, H. \& Salome,

H.

(2013).

Psychological Wellbeing Scale for University Youth, Psychological Counseling Journal, Faculty of Education,
Ain Shams University, Egypt, No. (36), pp:(673-694).

28- Sherry, L. \& Bryan, J. (2013). An Examination of Relationship Between Psychological Well-Being and Depression and Leisure Activity Participation Among Older Adults, Article, Loisir et Societe, Vol. (18), No. (1), pp:(67-92).

29- Shuwaikh, H. (2010). The study of predictive symptoms in the age of aging - a predictive study in light of wisdom, happiness and public health assessment -, Journal of Arab Studies in Psychology, Association of Psychologists, Egypt, Vol. (9), No. (1).

30-Silvia, M., Ioseba, I., Ignacio, G., María, C., Nuria, O. \& Alan B. (2016). Psychometric properties of the Leisure Time Satisfaction Scale in family caregivers, Psicothema. Vol. (28), No. (2), pp:(207-213).

31- Tamannaeifar, M. \& Motaghedifard, M. (2014). Subjective well-being and its sub-scales among students: The study of role of creativity and self-efficacy, Thinking Skills and Creativity, Vol. (12), No. (1), pp:(37-42). 
32- Tebessüm, A., Merve, K., Metin, Y. \& İlyas, O. (2016). Examination of Life Satisfaction and Leisure Satisfaction Levels of Individuals Participating Sport Activities in their Lesiure Time, The Journal of Recreation and Sport, Vol. (5), No. (4), pp:(45-60).

33-Teresa, F. \& Ana,T. (2018). The Influence of Leisure Attitudes and Leisure Satisfaction on Adolescents' Positive Functioning: The Role of Emotion Regulation, journals Frontier in Psychology, Vol. (9), No. (1349), pp:(1-12).

34- Yassin, H., Shahin, H. \& Sarmini, I.(2014). A Friendship and psychological well-being among a sample of university students Journal of Faculty of Education, Faculty of Education, Benha University, Vol. (25), No.(97),Pa. (2), PP: (353-379). DOI:10.12816/0021924

35- Yu-Jin, C. (2018). Correlation between Leisure Activity Time and Life Satisfaction: Based on KOSTAT Time Use Survey Data, Article, Occupational Therapy International, Vol. (2018), pp:(1-9),

36- Zambianchi, M., Ricci, B. \& Pio, E. (2009). Subjective well-being, coping styles, perceived Physical and mental health in the fourth age, Ricerche di Psicologia, Vol. (32), No. (1), PP: (135-150). 